\title{
A ingerência contratual e os danos a Administração Pública Municipal
}

\author{
The contractual infringement and damages to Municipal Public Administration \\ La infracción contractual y daños a la Administración Pública Municipal
}

Recebido: 08/10/2021 | Revisado: 13/10/2021 | Aceito: 23/10/2021 | Publicado: 25/10/2021

\author{
Ricardo Ovídio de Oliveira Lima \\ ORCID: https://orcid.org/0000-0002-1645-7537 \\ Faculdade São Vicente, Brasil \\ Universidade Potiguar, Brasil \\ E-mail: ricardooliveira-adv@ hotmail.com \\ Thalita Kelle Pires Beserra \\ ORCID: https://orcid.org/0000-0003-2693-8702 \\ Faculdade São Vicente, Brasil \\ Universidade Potiguar, Brasil \\ E-mail: tpiresb@gmail.com \\ Pedro Victor Miranda de Oliveira \\ ORCID: https://orcid.org/0000-0003-0478-8766 \\ Universidade Estadual do Piauí, Brasil \\ E-mail: pedrovictormiranda48@gmail.com \\ Jhonatha Magalhães Silva \\ ORCID: https://orcid.org/0000-0002-8120-8713 \\ Christus Faculdade do Piauí, Brasil \\ E-mail:jhonathamagalhaes0708@gmail.com \\ Jose Rosman Varjão Alves de Albuquerque \\ ORCID: https://orcid.org/0000-0003-4097-4478 \\ Centro Universitário do Rio São Francisco, Brasil \\ E-mail: j.rosman.albuquerque@hotmail.com \\ Isabele Thalyta Oliveira Andrade de Melo \\ ORCID: https://orcid.org/0000-0001-6771-3652 \\ Centro Universitário do Rio São Francisco, Brasil \\ E-mail: isabelethalyta.adv@gmail.com \\ Nilton Soares Formiga \\ ORCID: https://orcid.org/0000-0003-4907-9736 \\ Universidade Potiguar, Brasil \\ E-mail: nsformiga@yahoo.com
}

\begin{abstract}
Resumo
O presente artigo tem por finalidade analisar a problemática da gerencia contratual e os danos que a ingerência contratual traz à administração publica municipal. A perfeita gestão dos contratos da administração pública minimiza os problemas e eventuais falhas de cumprimento e de entrega. Essa perfeição de gerência passa essencialmente por um firme contrato de realização e uma delegação de responsabilidade a outros agentes públicos, fazendo com que esse escolhido tenha uma responsabilidade peculiar, qual seja, a conferência absoluta do cumprimento do contrato. Para que tais questões sejam poupadas é admirável que o gerenciamento contratual ocorra de forma prudente e responsável. Pode-se dizer também que a probidade deve disciplinar todo o ciclo de vida do contrato. O artigo também versa sob a responsabilidade gestor público, a partir do seu direito de delegação de um ato administrativo o mesmo continua vinculado à responsabilidade sobre o que se delegou. O gestor tem a obrigação de realizar uma boa escolha na indicação do fiscal de contrato, no sentido de que, em delegando servidores despreparados, estará o gestor público assumindo para si os riscos que podem advir da má escolha. Além de indicar responsavelmente o gestor, deverá o agente público oferecer meios de capacitação a fim de que o gerenciamento que houver, seja realizado de forma aperfeiçoada. Além do mais, o gestor/fiscal de contratos deve ter ciência que por conta de suas atribuições legais, ele tem competência para gerir e decidir, o que o torna detentor de responsabilidade sobre aquele objeto ora administrado, assim deverá geri-lo adequadamente para que não recaiam sobre si as consequências de Lei.
\end{abstract}

Palavras-chave: Administração municipal; Gestão de contratos; Responsabilizações.

\begin{abstract}
The purpose of this article is to analyze the problem of contractual management and the damage that contractual interference brings to the municipal public administration. The perfect management of public administration contracts minimizes problems and eventual failures in performance and delivery. This perfection of management essentially involves a firm contract for performance and a delegation of responsibility to other public agents, which means that the chosen one has a particular responsibility, namely the absolute verification of the contract's performance. In order for such issues to be spared, it is admirable that the contractual management takes place in a prudent and responsible
\end{abstract}


manner. It can also be said that probity must govern the entire life cycle of the contract. The article also deals with the responsibility of the public manager, since he has the right to delegate an administrative act, he continues to be bound by the responsibility for that which has been delegated. The manager has the obligation to make a good choice when appointing the contract inspector, in the sense that by delegating unprepared employees, the public manager will be assuming the risks that may arise from a bad choice. In addition to responsibly appointing the manager, the public agent must offer training so that the management, if any, can be done in an improved manner. Furthermore, the contract manager/fiscal must be aware that, due to his legal attributions, he has the competence to manage and decide, which makes him responsible for that administered object, so he must manage it properly so that the consequences of the Law do not fall upon him.

Keywords: Municipal administration; Contract management; Accountability.

\section{Resumen}

El objetivo de este artículo es analizar el problema de la gestión de los contratos y los perjuicios que la interferencia contractual acarrea a la administración pública municipal. La perfecta gestión de los contratos de la administración pública minimiza los problemas y eventuales fallos de cumplimiento y entrega. Este perfeccionamiento de la gestión implica esencialmente un contrato firme de ejecución y una delegación de responsabilidad en otros agentes públicos, de modo que este elegido tiene una responsabilidad particular, que es la verificación absoluta de la ejecución del contrato. Para evitar estos problemas, es admirable que la gestión contractual se realice de forma prudente y responsable. También se puede decir que la probidad debe regir todo el ciclo de vida del contrato. El artículo también trata de la responsabilidad del gestor público, ya que desde su derecho a delegar un acto administrativo sigue vinculado a la responsabilidad de lo delegado. El gestor tiene la obligación de hacer una buena elección en el nombramiento del inspector de contratos, en el sentido de que al delegar en empleados no preparados, el gestor público estará asumiendo los riesgos que puedan derivarse de una mala elección. Además de designar responsablemente al gestor, el agente público debe ofrecerle formación para que la gestión que pueda realizar se lleve a cabo de forma mejorada. Además, el gestor/fiscal del contrato debe ser consciente de que, por sus poderes legales, tiene la facultad de gestionar y decidir, lo que le convierte en el titular de la responsabilidad sobre ese objeto ahora administrado, por lo que debe gestionarlo adecuadamente para que no recaigan sobre él las consecuencias de la Ley.

Palabras clave: Administración municipal; Gestión de contratos; Responsabilidad.

\section{Introdução}

O legislador não está inerte quanto ao zelo nos procedimentos das atividades desempenhadas pelos servidores e agentes da Administração, de modo que o disposto no compêndio de Leis está também diretamente relacionado com os princípios que regem a Administração Pública, em destaque os da legalidade, moralidade e eficiência, os quais devem permear as boas práticas das atividades desempenhadas por seus funcionários.

O gestor público deve ter ciência que a delegação de um ato administrativo como o de gerenciar contratos não afasta a sua responsabilidade sobre o que se delegou. O gestor tem a obrigação de realizar uma boa escolha na indicação do fiscal de contrato, no sentido de que, em delegando servidores despreparados, estará o gestor público assumindo para si os riscos que podem advir da má escolha.

Assim além de indicar responsavelmente o gestor, deverá o agente público oferecer meios de capacitação a fim de que o gerenciamento que houver, seja realizado de forma aperfeiçoada. Além do mais, o gestor/fiscal de contratos deve ter ciência que por conta de suas atribuições legais, ele tem competência para gerir e decidir, o que o torna detentor de responsabilidade sobre aquele objeto ora administrado, assim deverá geri-lo adequadamente para que não recaiam sobre si as consequências de Lei.

\section{Metodologia}

Durante a pesquisa realizada para construção deste artigo, fez-se necessário seguir as normas procedimentais para elaboração de estudos científicos. É relevante a utilização da metodologia, uma vez que a partir dela pode-se traçar a problemática e objetivos com a finalidade de se obter bases que indicarão resultados sobre a temática levantada.

De outra sorte, o presente estudo teve característica teórica, onde se analisou a literatura levantada na revisão bibliográfica que deram subsídios para que fosse abordado o objeto, com vistas a esquadrinhar o problema, gerando 
informações pertinentes, as quais foram relatadas através do método exploratório que proporcionou a realização da análise de dados (Mezzaroba \& Monteiro, 2009).

Segundo Gil (2002), a pesquisa exploratória: “[...] tem como objetivo principal o aprimoramento de ideias ou a descoberta de intuições. Seu planejamento é bastante flexível, de modo que possibilite a consideração dos mais variados aspectos relativos ao fato estudado".

Em sendo assim, por meio do levantamento bibliográfico realizado, foi possível obter informações sobre as atribuições que cercam os gestores de contratos, bem como as punições existentes quando não é realizada a correta gerência contratual; assim, conseguiu-se examinar o que trata a doutrina e lei no que corresponde às responsabilidades objetivas e subjetivas do gestor público no tocante ao cometimento de práticas que gerem danos à Administração; analisando-se, por fim, através de julgados, casos práticos de condenação de agentes e servidores públicos que incidiram em práticas ilegais na fiscalização da peça de contrato.

Ainda, quanto à pesquisa bibliografia realizada, Lakatos e Marconi (2001) ensinam que a pesquisa bibliográfica, ou de fontes secundárias, abrange toda bibliografia já tornada pública em relação ao tema de estudo, desde publicações avulsas, boletins, jornais, revistas, livros, pesquisas, monografias, teses, material cartográfico etc., até meios de comunicação orais: rádio, gravações em fita magnética e audiovisuais: filmes e televisão. Sua finalidade é colocar o pesquisador em contato direto com tudo o que foi escrito, dito ou filmado sobre determinado assunto, inclusive conferências seguidas de debates que tenham sido transcritos por alguma forma, querem publicadas, quer gravadas.

\section{Resultados e Discussão}

A finalidade do estabelecimento de contratos entre a Administração e um particular é atingir o interesse público, contemplando as demandas da comunidade. Para que tais questões sejam preservadas é importante que o gerenciamento contratual ocorra de forma prudente e responsável. É salutar dizer também que a probidade deve disciplinar todo o ciclo de vida do contrato, que perpassam por fases já explicitadas no título anterior.

Cumpre relatar que o gestor deve estar preparado para gerenciar todas as fases do contrato, principalmente no que tange à execução, pois é nesta seara onde encontrará maiores desafios, devendo empregar seu conhecimento sobre gestão e o objeto contemplado. Assim, na relação entre gestor e fornecedor é comum que ocorra divergências, devendo o gestor sempre fazer sobressair a supremacia da Administração em relação ao contratado.

Para tanto, é necessário que o gestor de contratos esteja adequadamente capacitado para atender as necessidades da Administração, imprimindo zelo em sua atividade, prevenindo danos à máquina pública. De outra sorte, é de responsabilidade da Administração o fornecimento de meios para que a atividade em comento seja adequadamente satisfeita. Senão, vejamos:

Assim, o aprimoramento da Administração é fundamental, e pode se dar pela conjugação de diferentes modos de intervenção, seja pela modernização da máquina administrativa, seja pela capacitação do quadro de servidores, seja, ainda, pelo uso responsável dos recursos, respeitando-se os princípios da moralidade, da legalidade, da impessoalidade, da economicidade e da eficiência, entre outros (Manual do Prefeito, 2009, p.7).

Tendo em vista o citado, conclui-se que para exercer as atribuições com tranquilidade na fiscalização contratual, não se pode obstar a tecnicidade necessária, na medida em que, de acordo com o lecionado por Meirelles (1995), os gestores da coisa pública, estão investidos de competência decisória, revestindo-se como autoridades, qualificados com poderes e deveres específicos do cargo ou da função e, consequentemente, com responsabilidades inerentes às suas atribuições.

Como menciona Lima et al (2021) havendo ingerências administrativas na fiscalização do contrato e ocorrendo a malversação do dinheiro público, quando, por exemplo, sobrevém o atesto de forma culposa ou dolosa de uma nota fiscal 
superfaturada do objeto do contrato, tais irregularidades deverão ser apuradas, tomando-se as devidas providências para com o agente (s) causador (es) do dano.

O Tribunal de Contas da União - TCU (2014) disponibilizou um modelo de execução do objeto do contrato para aquisições públicas, e expôs algumas definições sobre o que seriam atos de ingerências, tais como:

- $\quad$ exigência dos funcionários da contratada trabalharem dentro das instalações do órgão sem justificativa;

- $\quad$ submissão dos funcionários da contratada à avaliação do órgão, tais como exames de admissão, entrevistas ou assemelhados;

- $\quad$ definição dos salários a serem pagos pela contratada aos seus funcionários;

- $\quad$ exigência de assinatura de Termo de Responsabilidade e Sigilo para acesso às informações e aos sistemas do órgão diretamente junto aos funcionários da contratada, devendo-se exigir que a contratada obtenha esse compromisso junto aos seus funcionários, bem como a fiscalização de seu fiel cumprimento;

- $\quad$ indicação de pessoa para ser contratada pelo fornecedor.

Ficam, portanto, proibidos tais comportamentos do órgão público contratante, devendo o Administrador observar o disposto para não pôr em riscos a execução contratual, nem muito mesmo a lisura no trato com o fornecedor, obstando assim o risco de incorrer em improbidade administrativa.

Com o objetivo de se ter uma execução plena do contrato, as cláusulas constantes nos termos devem ser claras e precisas, prevendo todos os direitos e obrigações, fazendo menção das especificidades do objeto a ser executado ou entregue, preservando as condições que foram anteriormente estabelecidas no termo de referência e/ou projeto básico da licitação. Em posse de todas essas informações terá o gestor um guia do que deverá observar no gerenciamento, podendo inclusive fazer um check-list a fim de facilitar a fiscalização do contrato.

Ocorre que em contratos mais complexos a exemplo de vigilância e limpeza urbana, onde existe a contratação de mão de obra terceirizada, a sua observância torna-se mais profunda, pois além de verificar medições, deve-se também fiscalizar se a empresa tem honrado com as obrigações previdenciárias da mão de obra realizadora do serviço. Tal situação da mão de obra é uma obrigatoriedade jurídica, vez que estão prestando um serviço à Administração, e esta por sua vez tem o dever de zelar pela correta aplicação dos valores firmados em contrato, podendo responder solidariamente nos termos do art. 31 da Lei $\mathrm{n}$. 8.212/91, de acordo com o $\S 2^{\circ}$ do art. 121 da Lei n. 14.133/21. Lembrando que este tipo de contratação (mão de obra) não gera vínculo trabalhista com o poder público.

Em se tratando da inadimplência das obrigações trabalhistas pela contratada empregadora é importante evidenciar o entendimento pacificado do Tribunal Superior do Trabalho - TST, através da Súmula 331 (2011), versando que caso haja conduta culposa na fiscalização do cumprimento das obrigações contratuais da prestadora de serviço a Administração Pública responderá de forma subsidiária desde que haja participado da relação processual. Frise-se que a Súmula destaca que a responsabilidade não será gerada com a tônica de mero inadimplemento trabalhista; assim terá que o administrador público comprovar se fez ou não uma correta fiscalização, e em não sendo atestado que houve um gerenciamento contratual probo, haverá a responsabilização.

O Supremo Tribunal Federal - STF (2010) também analisou a questão da responsabilização da Administração Pública no caso de inadimplência de verbas trabalhistas e previdenciárias, declarando constitucional através da Ação Declaratória de Constitucionalidade - ADC n. 16, a inteligência do $\S 1^{\circ}$ do art.. 121 da Lei n. 14.133/21, impondo limites à súmula n. 331 do TST, a qual sofreu alteração para adequar-se ao disposto pelo STF. Nisto, firmou-se o entendimento que a Administração poderá ser responsabilizada desde que seja provado que houve falha ou falta de fiscalização pelo órgão público contratante, analisando-se caso a caso.

Ainda dando continuidade em sede de responsabilização judicial dos atos praticados nos gerenciamentos contratuais, 
o TCU, através do acórdão n. 695/2003 da 1a câmara, condenou responsabilizando solidariamente os agentes públicos responsáveis pelo atesto de notas fiscais e pagamento de um serviço que ainda não havia sido cumprido, nem tampouco iniciado. Vejamos a decisão:

VISTOS, relatados e discutidos estes autos de Tomada de Contas Especial, de responsabilidade das pessoas físicas e jurídicas especificadas no item 3 retro, instaurada em razão da execução apenas parcial do objeto pactuado nos Convênios Incra AP/5.007/98 e AP/8.006/98, celebrados com o Município de Pedra Branca do Amapari/AP, que tinha por objeto a instalação de linhas de transmissão de energia de alta e baixa tensão.

Considerando que as irregularidades apuradas ensejam a aplicação da penalidade prevista no art. 57 da Lei ${ }^{\circ}$ 8.443/92;

Considerando os indícios de desvio de recursos e de falsidade material;

Considerando o parecer da Unidade Técnica, ratificado pelo Ministério Público junto a esta Corte, pela imputação de débito e aplicação de multa aos responsáveis;

ACORDAM os Ministros do Tribunal de Contas da União, reunidos em Sessão de $1^{\text {a }}$ Câmara, com fundamento no art. $1^{\circ}$, inciso I, da Lei $\mathrm{n}^{\circ} 8.443 / 92$, pelas razões expostas pelo Relator, em:

$[\ldots]$

9.3. condenar, com fundamento nos arts. 16, inciso III, alínea "d", e 19 da referida Lei, os Srs. Juares Gomes, Benjamim dos Santos Reis, Américo Távora da Silva e a empresa D.D. Rodrigues-ME, solidariamente, ao pagamento da quantia de $\mathrm{R} \$ 24.332,41$ (vinte e quatro mil, trezentos e trinta e dois reais e quarenta e um centavos), fixando-se o prazo de quinze dias, a contar da notificação, para que seja comprovado, perante o Tribunal (art. 214, inciso III, alínea "a", do Regimento Interno), o recolhimento da dívida aos cofres do Instituto Nacional de Colonização e Reforma Agrária - Incra, atualizada monetariamente e acrescida dos juros de mora calculados a partir de 22/07/1998 até a data do efetivo recolhimento, na forma prevista na legislação em vigor;

9.4. condenar, com fundamento nos arts. 16, inciso III, alínea "d", e 19 da Lei $\mathrm{n}^{\circ}$ 8.443, os Srs. Juares Gomes e Benjamim dos Santos Reis, solidariamente, ao pagamento da quantia de $\mathrm{R} \$ 203.452,58$ (duzentos e três mil, quatrocentos e cinqüenta e dois reais e cinquienta e oito centavos), fixando-se o prazo de 15 (quinze) dias, a contar da notificação, para que seja comprovado, perante o Tribunal (art. 214, inciso III, alínea "a", do Regimento Interno), o recolhimento da dívida aos cofres do Instituto Nacional de Colonização e Reforma Agrária - Incra, atualizada monetariamente e acrescida dos juros de mora calculados a partir de 21/07/1998 até a data do efetivo recolhimento, na forma prevista na legislação em vigor;

9.5. aplicar às pessoas físicas e jurídicas citadas nos itens 9.3 e 9.4, retro, a multa prevista no art. 57 da Lei ${ }^{\circ}$ 8.443/92 c/c o art. 267 do Regimento Interno, nos valores a seguir indicados, fixando-se o prazo de 15 (quinze) dias após o recebimento das respectivas notificações para que seja comprovado, perante o Tribunal, o recolhimento da dívida aos cofres do Tesouro Nacional, prazo após o qual o valor devido será acrescido dos encargos legais até a data do efetivo recolhimento (TCU, Acórdão n. 695/2003 - 1ª Câmara, Relator: Augusto Sherman, Data de julgamento: 15/04/2003, p.1, grifo nosso).

Vale também trazer no presente artigo trecho do acórdão n. 859/2006, do plenário do TCU, que também condenou agentes públicos solidariamente em razão da malversação do erário em execução contratual, com o seguinte entendimento:

O agente público que deixa de exigir da contratada a prestação das garantias contratuais, conforme previsto no art. 56 da Lei n ${ }^{\circ} 8.666 / 93$, responde pelos prejuízos decorrentes de sua omissão, bem como às penas previstas nos arts. $57 \mathrm{e}$ 58 da Lei $n^{\circ}$ 8.443/92. 3. A negligência de fiscal da Administração na fiscalização de obra ou acompanhamento de contrato atrai para si a responsabilidade por eventuais danos que poderiam ter sido evitados, bem como às penas previstas nos arts. 57 e 58 da Lei ${ }^{\circ} 8.443 / 92$. 4. A comprovação do superfaturamento faz surgir para os envolvidos o dever de ressarcir à Administração os valores indevidamente recebidos. 5. Os juros moratórios tem caráter penal e só cabem quando evidenciada a existência de má-fé. Afastada a hipótese de má-fé, deixam de integrar o valor devido (TCU, Acórdão n. 859/2006 - Plenário. Relator: Marcos Vinicios Vilaça. Data de julgamento: 07/06/2006, grifo nosso).

Da análise dos acórdãos acima descritos vê-se que houve a condenação em conformidade com a legislação pertinente aos agentes públicos e pessoas jurídicas envolvidas. E, das condutas antijurídicas evidenciadas no acórdão 695/2003, é visto o prejuízo gerado ao município e região por não haver a instalação de rede elétrica para a área contratada, existindo assim prejuízo à localidade que seria contemplada com o benefício, prejudicando também a população que fosse utilizar aquele serviço. 
Em se tratando também do acórdão 695/2003 que analisou e julgou a ingerência na fiscalização do contrato, o Ministério da Economia em sua instrução normativa n. 05/2017, traz pormenorizado quais norteamentos de fiscalização devem ocorrer para que se evite falta de controle sobre o contrato. Em sendo assim, em seu artigo 40 especificou alguns tipos de fiscalização, dentre elas destacamos: 1 - a fiscalização técnica: que compreende avaliar se o contrato está sendo executado nos moldes contratados, aferindo qualidade, quantidade, tempo, forma do serviço a fim de perceber se estão atendendo satisfatoriamente o desenvolvimento do serviço contratado, com o objetivo de também realizar o pagamento corretamente, sem valores à maior ou a menor injustificadamente; 2 - fiscalização administrativa: que ocorre nos casos de dedicação exclusiva de mão de obra, onde o gestor responsável deve observar na execução se a empresa está atendendo às obrigações previdenciárias, fiscais e trabalhistas, tomando as medidas cabíveis tempestivamente no caso de inadimplementos.

O Tribunal Regional da $5^{a}$ Região - TRF-5, julgou Ação Civil Pública - ACP em sede de improbidade administrativa, condenando os agentes públicos que se utilizaram da licitação e consequente contrato para compra de veículos superfaturados, beneficiando empresa contratada. A seguir, decisão:

AÇÃO CIVIL PÚBLICA. IMPROBIDADE ADMINISTRATIVA. EX-PREFEITO E SERVIDORES DO MUNICÍPIO DE ANADIA-AL. NÃO APLICAÇÃO DA LEI No 8.429/92 A AGENTES PÚBLICOS MUNICIPAIS AFASTADA. IRREGULARIDADES NA APLICAÇÃO DE VERBAS FEDERAIS NA EXECUÇÃO DOS CONVÊNIOS 2099/2002 e 840/2002 DA UNIÃ̃O FEDERAL. FRACIONAMENTO DE LICITAÇÃO. SUPERFATURAMENTO. FRAUDE À LICITAÇÃO. MÁ-FÉ CARACTERIZADA. [...]

1. Apelações do ex-prefeito e dos servidores do Município de Anadia-AL em face da sentença que julgou procedente ação civil pública de improbidade administrativa. Houve condenação dos réus em razão de irregularidades constatadas na licitação e aplicação de recursos públicos na execução dos Convênios nº 2099/2002 e 840/2002, apurado pela "Operação Sanguessuga" da Polícia Federal que fiscalizava a compra de unidades móveis de saúde. Os réus foram condenados ao ressarcimento integral do dano, no valor de $\mathrm{R} \$ 13.703,44$; suspensão dos direitos políticos e proibição de contratar com o Poder Público por cinco anos; perda da função pública e multa civil no valor do dano. [...]

4. Configura ato de improbidade a constatação de irregularidades no uso de verbas públicas na compra de veículos para atendimento médico da população, tais como: fracionamento indevido de licitação, superfaturamento de preço, fraude à licitação, aumento irregular do valor da contrapartida do Município e favorecimento de empresa determinada, causando prejuízo à comunidade e ao erário (arts. 10, V, VIII, XII e 11, caput, da LIA).

5. As sanções aplicadas aos réus observaram estritamente aos princípios da razoabilidade e proporcionalidade, tendo em vista a extensão, a gravidade das condutas praticadas pelos réus bem como o dano à população decorrente dos atos ímprobos. [...] (TRF-5 - AC: 200980000022752, Relator: Desembargador Federal Marcelo Navarro, Data de Julgamento: 05/09/2013, Terceira Turma, Data de Publicação: 11/09/2013, grifo nosso).

Como se vê, os danos à administração pública municipal perpassam por todos os agentes envolvidos que responderão pela conduta ilícita cometida que gerou prejuízo ao erário e deficiência no atendimento à população, a qual nesse caso era a figura mais necessitada da tutela municipal. Importante salientar que no fato em questão tem-se afronta direta aos direitos humanos e dignidade da pessoa humana vez que a população sofreu pela falta precisa dos veículos para levar o atendimento médico necessário.

\section{Considerações Finais}

O presente artigo buscou analisar a ingerência contratual que pode se transformar em uma das maiores causas de prejuízo ao dinheiro público e assim à administração pública como um todo. O problema dessa falta de zelo ou muitas das vezes da própria conduta dolosa em fraudar contratos e licitações em benefício próprio ou de outrem é que compromete a qualidade do serviço público prestado, prejudicando a correta gestão da máquina pública e consequentemente o governo de políticas públicas para o município.

É imprescindível que a indicação de gestores seja realizada de forma proba e com critérios objetivos leais. O que se percebe é que a escolha principalmente na gestão municipal de cidades pequenas onde a maioria dos indicados são cargos 
comissionados e contratados por meio de processos seletivos através de arranjos políticos é que os ditos servidores tendem a satisfazer as vontades do administrador público sem, todavia, esquadrinhar a lei para saber se aquela sua atividade desempenhada na gestão e fiscalização do contrato é permitido em lei, o que ocasiona muita das vezes ilícitos, que vem a recair em responsabilizações e improbidades.

Assim, deve-se tornar integral a qualificação e aperfeiçoamento dos envolvidos nessas relações contratuais a fim de que sejam realizadas as atividades da função, de forma responsável e dentro dos quesitos de Lei.

A posterior analise da efetiva aplicação da nova lei, baseará a continuação desse estudo, de forma a ver quais as novas aplicações foram efetivadas e as que não tiveram proveito efetivo.

\section{Referências}

Brasil. (1988). Constituição da República do Brasil de 1988. <http://www.planalto.gov.br/ccivil_03/Constituicao/Constituicao.htm.

Brasil. (2021). Lei $N^{o} 14.133$, de $1^{o}$ de abril De 2021. < http://www.planalto.gov.br/ccivil_03/_ato2019-2022/2021/lei/L14133.htm>.

Brasil. (2017). Ministério da Economia, Instrução Normativa $n .05$ de 26 de maio de $2017 . \quad<$ https://www.comprasgovernamen tais.gov.br/index.php/legislacao/instrucoes-normativas/760-instrucao-normativa-n-05-de-25-de-maio-de-2017>.

Brasil. (2021). Supremo Tribunal Federal, Ação declaratória de constitucionalidade n. 16/DF-Distrito Federal. Relator: Ministro Cezar Peluso. Pesquisa de Jurisprudência.http://stf.jus.br/portal/jurisprudencia/listarJurisprudencia.asp?s1=\%28A\%C7\%C3O+DIRETA+DE+CONSTITUCIONALIDADE\%29\%2816\% 2ENUME\%2E+OU+16\%2EACMS\%2E\%29\&base=baseAcordaos\&url=http://tinyurl.com/y5u2vwxd..

Brasil. (2003). Tribunal de Contas da União, Acórdão n. 695/2003 - $1^{\text {a }}$ Câmara, Relator: Ministro Augusto Sherman. Tomada de Contas Especial (TCE). Pesquisa de Jurisprudência. https://pesquisa.apps.tcu.gov.br/\#/documento/acordao-completo/695/NUMACORDAO\%253A695\%2520 ANOACORDAO\%2 53A2003/DTRELEVANCIA\%20desc,\%20NUMACORDAOINT\%20desc/1/\%20?uuid=a3ddef40-54dc-11e9-8628-558d24a9d311.

Brasil. (2006). Tribunal de Contas da União, Acórdão n. 859/2006 - Plenário, Relator: Ministro Marcos Vinicios Vilaça. Pesquisa de Jurisprudência. <https://pesquisa.apps.tcu.gov.br/\#/documento/acordaocompleto/1084820036.PROC/NUMACORDAO\%253A859\%2520ANOACORDAO\%253A2006/DTR ELEVANCIA\%20desc,\%20NUMACORDAOINT\%20desc/0/\%20?uuid=9679e0f0-54e3-11e9-9a38-0f046d648e43.

Brasil. (2011). Tribunal Superior do Trabalho, Súmula n. 331. Contrato de prestação de serviços. Legalidade (nova redação do item IV e inseridos os itens V e VI à redação) - Res. 174/2011, DEJT divulgado em 27, 30 e 31.05.2011. Súmulas da Jurisprudência Uniforme do Tribunal Superior do Trabalho. http://www.tst.jus.br/web/guest/sumulas.

Brasil. (2013). Tribunal de Contas da União, Responsabilização de Agentes Segundo a Jurisprudência do TCU - Uma Abordagem a partir de Licitações e Contratos.https://portal.tcu.gov.br/biblioteca-digital/responsabilizacao-de-agentes-segundo-a-jurisprudencia-do-tcu-uma-abordagem-a-partir-de-licitacoes-econtratos-aulas-1-a-5.htm.

Breda, Juliano (coord.). Crimes de Licitação e Contratações Públicas, RT (2021).

Carvalho, Matheus. (2019). Manual de direito administrativo. JusPODIVM (2019).

Enap. (2018). Manual de Gestão e de Fiscalização de Contratos de Serviços Terceirizados da Enap, Portaria/ENAP n. 57.

Filho, J. (2012). Manual de Direito Administrativo. Atlas.

Filho, M. (2010). Curso de Direito Administrativo. Fórum.

Gil, A. (2012). Como Elaborar Projetos de Pesquisa. Atlas.

Ibam. (2009). Manual do Prefeito. IBAM.

Justen Filho, Marçal. (2019) Comentários à lei de licitações e contratos administrativos. (18a ed.), Revista dos Tribunais

Justen Filho, Marçal. (2021) Comentários à Lei de Licitações e Contratações Administrativas, Thomson Reuters

Lakatos, E. \& Marconi, M. (2001). Fundamentos de Metodologia Científica. Atlas.

Leite, J., Souza, H. \& Nascimento, E. 2010. Contratualização na saúde: proposta de um contrato único para os programas no Estado de Minas Gerais, RAS, 12(46).

Lima, R. Beserra, T. \& Formiga, N. (2021). Public contracts and their management by the head of the municipal executive. Research, Society and Development, 10(10), e115101018382. https://doi.org/10.33448/rsd-v10i10.18382

Mazza, Alexandre. (2019) Manual de direito administrativo. (9a ed.), Saraiva

Meirelles, H. (1995). Direito Municipal Brasileiro. Malheiros.

Melo, C. (2005). Curso de Direito Administrativo. Malheiros Editores. 
Research, Society and Development, v. 10, n. 14, e63101421575, 2021

(CC BY 4.0) | ISSN 2525-3409 | DOI: http://dx.doi.org/10.33448/rsd-v10i14.21575

Monteiro, C., \& Mezzaroba, O. (2009). Manual de Metodologia da Pesquisa no Direito. Saraiva.

Pietro, M. (2014). Direito Administrativo. Atlas. 